\title{
Visual performance of an extended depth of focus intraocular lens for treatment selection
}

\author{
Thomas Kohnen $\mathbb{D}^{1} \cdot$ Myriam Böhm $^{1} \cdot$ Eva Hemkeppler $^{1} \cdot$ Sabrina Schönbrunn ${ }^{1}$. Nina DeLorenzo ${ }^{1}$ • \\ Kerstin Petermann ${ }^{1} \cdot$ Michael Herzog ${ }^{1}$
}

Received: 19 February 2019 / Revised: 12 March 2019 / Accepted: 2 April 2019 / Published online: 26 April 2019

(c) The Royal College of Ophthalmologists 2019

\begin{abstract}
Purpose To evaluate the visual performance of an extended depth of focus (EDOF) intraocular lens (IOL) for patient selection.

Methods This prospective non-comparative case series evaluated fifty-two eyes (26 patients) after bilateral implantation of the Tecnis Symfony IOL. Exclusion criteria were previous ocular surgeries, corneal astigmatism of $>1.5$ diopter, and ocular pathologies or corneal abnormalities. Uncorrected (UCVA) and distance-corrected (DCVA) visual acuity (VA) in $4 \mathrm{~m}$, $80 \mathrm{~cm}, 60 \mathrm{~cm}$ and $40 \mathrm{~cm}(\operatorname{logMAR})$, defocus curve, contrast sensitivity (CS) and a questionnaire on subjective quality of vision $(\mathrm{QoV})$ were assessed after 3 months.

Results UCVA was $-0.02 \pm 0.071 \log$ MAR at $4 \mathrm{~m}, 0.01 \pm 0.077 \log$ AAR at $80 \mathrm{~cm}, 0.08 \pm 0.187 \log$ AAR at $60 \mathrm{~cm}$ and $0.22 \pm 0.153 \log$ MAR at $40 \mathrm{~cm}$. Defocus curve testing showed a flat VA range from 0.00 to $-1.50 \mathrm{D}(-0.05-0.02$ $\log$ MAR). At near distance from -2.0 to $-2.5 \mathrm{D}$ a dip of DCVA was observed (0.14-0.28 logMAR). CS under photopic and mesopic conditions without and with glare was $1.56 \log \mathrm{CS}, 0.86 \log \mathrm{CS}, 0.78 \log \mathrm{CS}$, respectively. Spectacle independence was achieved in $100 \%$ for distance and intermediate vision and $71 \%$ of patients at near distance.

Conclusion This EDOF IOL provides excellent intermediate and far $(<0.1$ logMAR $)$ and acceptable near UCVA $(<0.3 \log$ MAR). Defocus curve testing confirmed an EDOF between far and intermediate distance and showed a dip at near distance. It provides good QoV, CS, high spectacle independence, perception of few optical phenomena, and particularly good night-driving capabilities.
\end{abstract}

\section{Introduction}

In the last decade, intermediate-working distances required for computer work and the use of smartphones and tablets, for example, have gained increased importance in patients' priorities. This has, in part, lead to a demand for spectacle independence at the intermediate distance.

These authors contributed equally: Thomas Kohnen, Myriam Böhm

Supplementary information The online version of this article (https:// doi.org/10.1038/s41433-019-0443-x) contains supplementary material, which is available to authorized users.

Thomas Kohnen

kohnen@em.uni-frankfurt.de

1 Department of Ophthalmology, Goethe University, Frankfurt am Main, Germany
Bifocal intraocular lenses (IOLs) with two focal points representing fixed working distances at far and near vision are not able to respond to that need and only deliver a sharp image on the patient's retina at these two "sweet spots", not in-between [1].

Thus, to address the patient's needs and desire for good intermediate visual acuity (VA), the principle of monovision was introduced and trifocal IOLs were developed [2-6].

First, the most cost-neutral alternative to meet these patients' expectations is to apply the principle of monovision by targeting for emmetropia for the dominant eye and near to intermediate distance for the non-dominant eye. However, the principle of monovision must be simulated prior to surgery in order to assess if the individual patient is able to tolerate it before identifying the appropriate treatment selection. Second, trifocal IOLs were designed with three peaks for distance, intermediate, and near vision, however, these peaks are associated with a loss of contrast sensitivity (CS) and increased occurrences of photopic phenomena such as halos and glare 
that affect patients' quality of vision, particularly reducing night-driving capabilities and, subsequently, their satisfaction with the treatment $[7,8]$.

A recently introduced extended depth of focus (EDOF) IOL (Tecnics Symfony ZXR00, Abbott Laboratories, Abbott Park, IL) was designed using new optical technology to generate an EDOF. The IOL aims to provide patients with improved VA at intermediate distances. According to the manufacturer, this technology uses a proprietary achromatic diffractive echelette design that corrects the corneal chromatic aberration for enhanced CS and generates an extended range of vision with incidences of halos and glare comparable to a monofocal IOL [9].

The aim of the current study was to analyze the visual performance of the EDOF IOL for treatment selection, particularly intermediate VA $(60 \mathrm{~cm}$ and $80 \mathrm{~cm})$, the range of depth of focus in defocus curve testing, CS, photopic phenomena, and subjective quality vision (QoV).

\section{Patients and methods}

\section{Study design}

This prospective, non-comparative study included twentysix patients after bilateral phacoemulsification and implantation of Tecnis Symfony IOL (Abbott Medical Optics, Inc., USA) 3 months postoperatively. The study was conducted from February $2^{\text {nd }}, 2016$, to November $11^{\text {th }}, 2017$. It adhered to the tenets of the Declaration of Helsinki and was approved by the local ethics committee of the Department of Ophthalmology at Goethe University in Frankfurt. The study was registered at ClinicalTrials.gov (registration number: NCT03223857). All patients signed an informed consent form.

\section{Statistical analysis}

The data are presented as the mean \pm standard deviation (SD). The statistical analysis was performed using SPSS ${ }^{\circledR}$ Statistics for Mac (version 24.0, International Business Machines Corp.).

\section{Patients}

Fifty-two eyes of twenty-six patients were enrolled after bilateral phacoemulsification and implantation of an EDOF IOL. Seven patients were not included in the study due to exclusion criteria. Four of them suffered from a comorbidity of the eye and three patients showed an astigmatism higher than $1.5 \mathrm{D}$. The lens explantation rate in this study was zero.

Patients were recruited to participate in the study after having surgery on either eye. The two surgeries took place within 2 weeks for all patients included in the study. The inclusion criteria were a bilateral cataract surgery with the implantation of Symfony IOL and a corneal astigmatism <1.5 D measured with Pentacam (Oculus, Wetzlar, Germany). Exclusion criteria were previous ocular surgeries, ocular pathologies or corneal abnormalities. Throughout this study, the study team: the surgeon, two investigators, an optician and the study coordinator, performing the surgery as well as all preoperative and postoperative measurements remained the same.

\section{Examinations}

Patients were examined 3 months after the second eye surgery to evaluate the primary outcome parameters of monocular and binocular uncorrected and distancecorrected VA at distance (UDVA, CDVA), intermediate distance $(80 \mathrm{~cm}, 60 \mathrm{~cm})$ (UIVA, DCIVA), and near distance $(40 \mathrm{~cm})$ (UNVA, DCNVA).

Postoperatively, all patients received a complete ophthalmological examination including manifest refraction, monocular and binocular UCVA and DCVA at all distances, Goldmann applanation tonometry, slit-lamp examination and funduscopy in mydriasis.

Monocular and binocular UCVA and DCVA at far (4 m), intermediate $(80 \mathrm{~cm}, 60 \mathrm{~cm})$, and near $(40 \mathrm{~cm})$ were performed using the $100 \%$ contrast Early Treatment Diabetic Retinopathy Study (ETDRS) chart under photopic light conditions $\left(167 \mathrm{~cd} / \mathrm{m}^{2}\right)$ in $\log$ MAR [10]. The VA in $60 \mathrm{~cm}$ was measured by means of the $40 \mathrm{~cm}$ chart and converted afterward. Binocular CS was measured under photopic $\left(167 \mathrm{~cd} / \mathrm{m}^{2}\right)$, mesopic $\left(0.167 \mathrm{~cd} / \mathrm{m}^{2}\right)$, and mesopic with glare light conditions by means of the "Frankfurt-Freiburg Contrast and Acuity Test System" (FF-CATS) [11]. Furthermore, monocular and binocular defocus curve testing from -5.0 to $+2.0 \mathrm{D}$ in $0.5 \mathrm{D}$ steps under photopic light conditions (ETDRS) was conducted.

Moreover, all patients completed a QoV questionnaire that included the following: (1) The presence of visual disturbances or photopic phenomena (6 items) - glare (trouble seeing street signs due to bright light or oncoming headlights), halos (rings around a light), double vision, ghosting, color perception (trouble recognizing specific colors), and distorted vision (straight lines look crooked), (2) Visual lifestyle activities (9 items): driving at day, driving at night, theatre/concert, watching TV, at home, cooking, using a computer/musical instrument, domestic work, and reading a newspaper, (3) Spectacle independence for distance, intermediate, and near vision (3 items), (4) Satisfaction: "Would you choose this IOL again?" The response rating scale for the visual disturbances and the spectacle independence was either yes or no. For lifestyle activity items, a scale of 1 (very good) to 6 (very bad) 
was used. Furthermore, patients were asked if they would choose the same IOL again and if they would recommend this IOL to others. (Quality of life questionnaire, supplementary document S1) This questionnaire is a summarized version of one used by Kohnen et al. previously [12]. The visual disturbance questions and lifestyle activities were based on a survey distributed in FDA clinical trials (Alcon, Inc. AcrySof IQ ReSTOR, physician labeling, 2009) and subscales of the National Eye Institute Visual Functioning Questionnaire-25 (NEIVFQ-25) [13]. The spectacle independence questions were similar to those in the modified Cataract Type Specification quality of life instrument [14].

\section{Surgical procedure}

The surgeries were all performed under topical anesthesia by the same experienced surgeon (T.K.). Twenty-one study participants received a capsulotomy, lens fragmentation, and corneal incisions using a LenSx femtosecond laser (Alcon Laboratories, Inc, Fort Worth, Texas, USA), and phacoemulsification was performed using the standard ultrasound technique (Infiniti, Alcon Laboratories, Inc, Fort Worth, TX, USA). In five patients, manual capsulorhexis, corneal incisions, and ultrasound lens fragmentation were performed. All patients received sutureless $2.3 \mathrm{~mm}$ corneal incisions located temporally.

\section{Study intraocular lens}

The Technics Symfony ZXR00 IOL (Abbott Medical Optics, Inc., CA, USA) is a foldable, single-piece, UVblocking hydrophobic acrylic, C-loop haptic multifocal IOL with a power addition of $+1.75 \mathrm{D}$ at the IOL plane. The biconvex wavefront-designed anterior aspheric surface (negative spherical aberration of $-0.27 \mu \mathrm{m}$ ) and the posterior achromatic diffractive surface are intended to correct chromatic aberration for enhanced CS and extended range of focus. The IOL has an overall diameter of $13 \mathrm{~mm}$, an optical zone of $6 \mathrm{~mm}$ and a refractive index of 1.47 at $35^{\circ} \mathrm{C}$. It is available in powers from +5.0 to $+34.0 \mathrm{D}$ in $0.5 \mathrm{D}$ increments. The lens has a frosted continuous $360^{\circ}$ posterior square edge. For IOL power calculations, the Haigis formula was used using axial length measurements, corneal power and anterior chamber depth measured by the IOL Master (IOL Master 500; Carl Zeiss Meditec, Jena, Germany, Software version 7.1) in all patients.

\section{Results}

The mean patient age was $69 \pm 8.089$ years [ $48-83$ years] and $31 \%$ ( 8 of 26 patients) were female. Cataract surgery was performed in all 26 patients; in 19\% (5 of 26 patients) standard manual phacoemulsification was performed, whereas $81 \%$ (21 of 26 patients) received femtosecond laser assisted cataract surgery. The mean lens power was $+18.55 \pm 5.330 \mathrm{D}[8.5-23.5 \mathrm{D}]$, the mean target refraction $-0.17 \pm 0.297 \mathrm{D}$ and the prediction error (target refraction spherical equivalent $(\mathrm{SE}))$ was $-0.15 \pm 0.324 \mathrm{D}$.

SE changed from $-1.17 \pm 3.310 \mathrm{D}[-8.6$ to $3.0 \mathrm{D}]$ preoperatively to $-0.03 \pm 0.284 \mathrm{D}[-0.88$ to $0.50 \mathrm{D}] 3$ months postoperatively. Furthermore, $96 \%$ (50 of 52 eyes) showed a SE accuracy of $\pm 0.5 \mathrm{D} 3$ months postoperatively (supplementary Fig. S2) and $100 \%$ (52 of 52 eyes) showed a postoperative refractive cylinder of $\pm 0.5 \mathrm{D}$ after 3 months (supplementary Fig. S3).

Three months after lens implantation the monocular and binocular uncorrected and distance-corrected VA at far, intermediate and near distance are shown in Table 1.

Cumulative monocular UCVA and DCVA at far, intermediate and near distance are shown in Fig. 1a-d. Fifty eyes (96\%) showed a UDVA of $0.00 \log$ MAR or better and all 52 eyes $(100 \%)$ a DCVA of minimum 0.0 logMAR (Fig. 1a). At $80 \mathrm{~cm}$ all 52 eyes $(100 \%)$ and at $60 \mathrm{~cm} 39$ eyes of $52(75 \%)$ eyes showed a UIVA of at least $0.1 \log$ MAR (Fig. 1b, c) and $69 \%$ (36 eyes of 52) showed a UNVA of minimum $0.3 \log$ MAR and $90 \%$ (47 eyes of 52) a UNVA of $0.5 \log$ MAR or better (Fig. 1d).

Figure 2 visualizes the postoperative monocular UDVA vs. postoperative DCVA and shows that for $90 \%$ (47 eyes of 52) UDVA is within one line of CDVA and that for 58\% (30 eyes of 52) UDVA is the same as CDVA.

Figure $3 \mathrm{a}, \mathrm{b}$ illustrates the depth of focus tested with the monocular and binocular defocus curve. The depth of focus between 0.00 and $-1.50 \mathrm{D}$ between far and intermediate distance showed a VA range of $0.09 \log$ MAR $(-0.06$ to $0.03 \log$ MAR) for the monocular defocus curve and of

Table 1 Logarithm of Minimal Angle of Resolution (logMAR) of monocular and binocular uncorrected and distance-corrected distance, intermediate and near visual acuity after implantation of extended depth of focus (EDOF) intraocular lens (Symfony) at 3 months postoperatively

\begin{tabular}{lcc}
\hline Parameters & Monocular $(n=52)$ & Binocular $(n=26)$ \\
\hline UDVA (mean \pm SD) & $0.01 \pm 0.089$ & $-0.02 \pm 0.071$ \\
DCVA (mean \pm SD) & $-0.05 \pm 0.061$ & $-0.06 \pm 0.081$ \\
UIVA $80 \mathrm{~cm}($ mean $\pm \mathrm{SD})$ & $0.04 \pm 0.087$ & $0.01 \pm 0.077$ \\
DCIVA $80 \mathrm{~cm}($ mean $\pm \mathrm{SD})$ & $0.03 \pm 0.083$ & $0.01 \pm 0.086$ \\
UIVA 60 cm (mean $\pm \mathrm{SD})$ & $0.08 \pm 0.144$ & $0.08 \pm 0.187$ \\
DCIVA 60 cm (mean $\pm \mathrm{SD})$ & $0.08 \pm 0.150$ & $0.09 \pm 0.166$ \\
UNVA (mean $\pm \mathrm{SD})$ & $0.30 \pm 0.145$ & $0.22 \pm 0.153$ \\
DCNVA (mean $\pm \mathrm{SD})$ & $0.30 \pm 0.144$ & $0.23 \pm 0.126$
\end{tabular}

UDVA uncorrected distance visual acuity, $C D V A$ corrected distance visual acuity, UIVA uncorrected intermediate visual acuity, DCIVA distance-corrected intermediate visual acuity, UNVA uncorrected near visual acuity, $D C N V A$ distance-corrected near visual acuity 
A
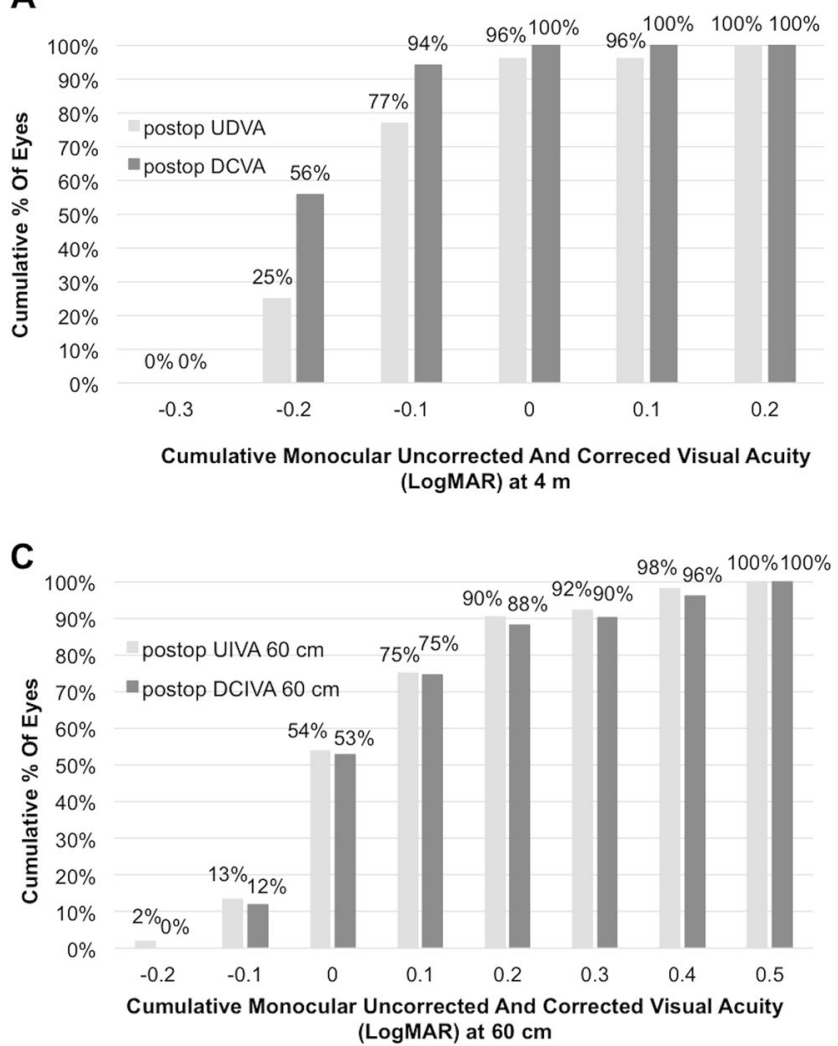

Fig. 1 a Cumulative monocular visual acuity at $4 \mathrm{~m}$ distance. Percentage of patients who achieved a certain cumulative monocular distance-corrected and uncorrected visual acuity in $\log$ MAR at 3 months after implantation of a Symfony IOL ( $n=52$ eyes). b Cumulative monocular visual acuity at $80 \mathrm{~cm}$ distance. Percentage of patients who achieved a certain cumulative monocular distancecorrected and uncorrected intermediate $(80 \mathrm{~cm})$ visual acuity in $\log$ MAR at 3 months after implantation of a Symfony IOL ( $n=52$ eyes). c Cumulative monocular visual acuity at $60 \mathrm{~cm}$ distance. Percentage of patients who achieved a certain cumulative monocular distancecorrected and uncorrected intermediate $(60 \mathrm{~cm})$ visual acuity in

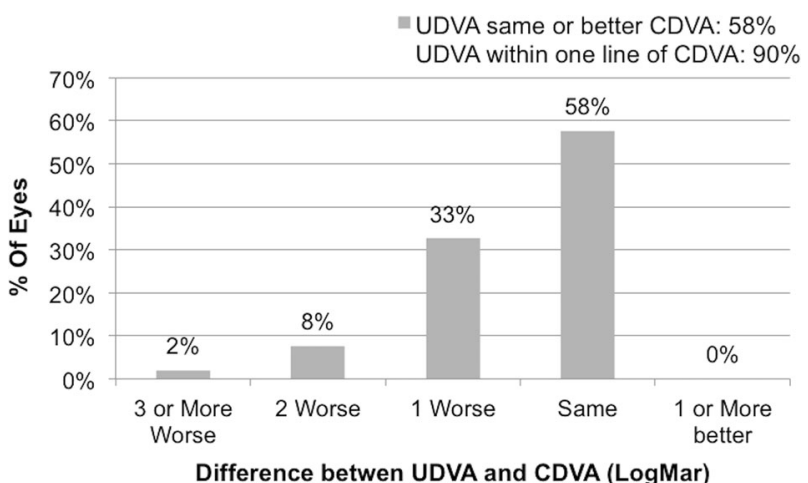

Fig. 2 Postoperative monocular uncorrected distance visual acuity vs. postoperative monocular corrected distance visual acuity 3 months after implantation of an extended depth of focus intraocular lens (Symfony IOL) $(n=52)$. UDVA uncorrected distance visual acuity, DCVA distance-corrected visual acuity
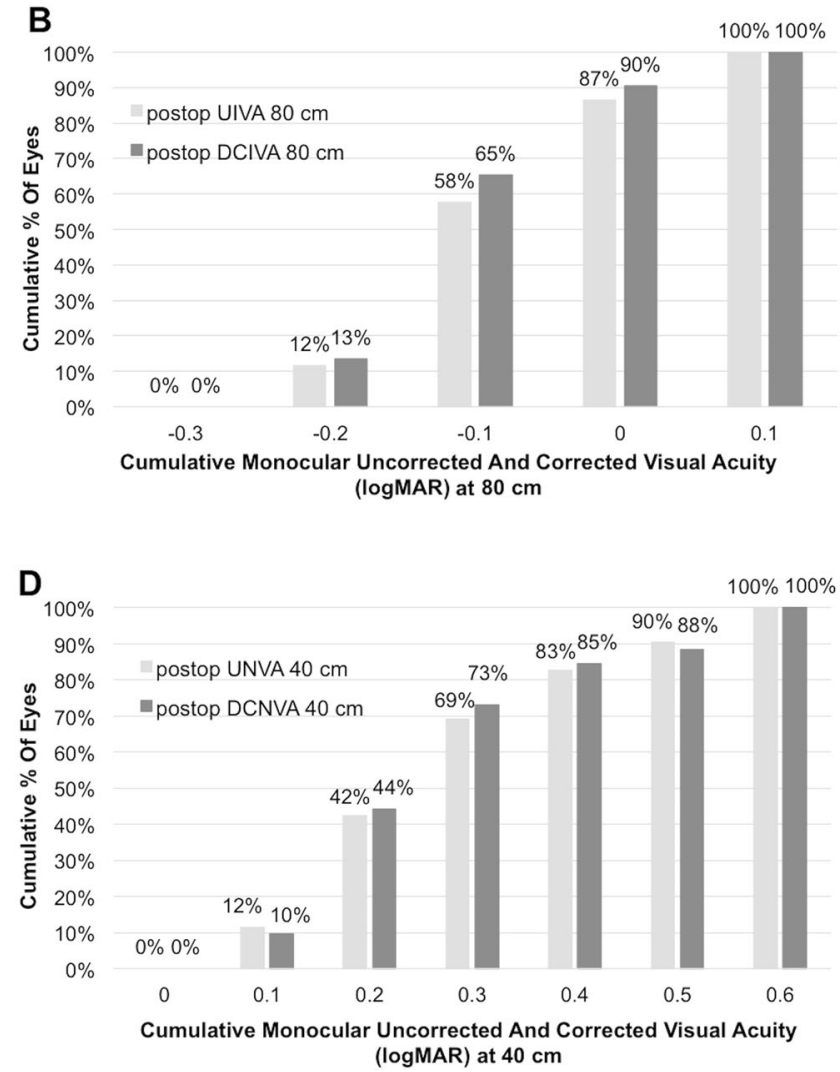

$\log$ MAR at 3 months after implantation of a Symfony IOL $(n=52$ eyes). (UIVA $=$ uncorrected intermediate visual acuity, DCIVA $=$ distance-corrected intermediate visual acuity). d Cumulative monocular visual acuity at $40 \mathrm{~cm}$ distance. Percentage of patients who achieved a certain cumulative monocular distance-corrected and uncorrected near visual acuity $(40 \mathrm{~cm})$ in $\log$ MAR at 3 months after implantation of a Symfony IOL $(n=52$ eyes). UNVA uncorrected near visual acuity, DCNVA distance-corrected near visual acuity, UIVA uncorrected intermediate visual acuity, DCIVA distance-corrected intermediate visual acuity, UDVA uncorrected distance visual acuity, DCVA distance-corrected visual acuity

$0.07 \log$ MAR ( -0.05 to $0.02 \log$ MAR) for the binocular defocus curve. The binocular defocus curve showed a maximum peak of $-0.05 \log$ MAR at defocus $0.00 \mathrm{D}(4 \mathrm{~m})$. In the intermediate range from -0.5 to $-1.5 \mathrm{D}(2 \mathrm{~m}$ to $67 \mathrm{~cm})$ a DCVA of -0.03 to $0.02 \log$ MAR was observed. At near distance from -2.0 to $-2.5 \mathrm{D}(50 \mathrm{~cm}$ to $40 \mathrm{~cm}) \mathrm{a}$ dip of DCVA of to $0.28 \log$ MAR can be seen. Overall, a DCVA of $0.3 \log$ MAR or better was achieved between the 0.00 and $-2.50 \mathrm{D}$ defocus in the monocular and binocular defocus curve.

The CS measured under photopic, mesopic, and mesopic with glare lighting conditions was $1.56 \pm 0.37,0.86 \pm 0.12$ and $0.78 \pm 0.12 \log C S_{\text {Weber }}$ (smallest detectable increment of CS of "Weber's law"), respectively.

Twenty-four of twenty-six patients filled out a questionnaire about subjective QoV. On a grading scale of 1 
Fig. 3 a Monocular defocus curve. Monocular distancecorrected defocus curve in logMAR 3 months after implantation of an extended depth of focus intraocular lens (Symfony IOL) ( $n=52$ eyes). b Binocular defocus curve. Binocular distance-corrected defocus curve in logMAR 3 months after implantation of an extended depth of focus intraocular lens (Symfony IOL) $(n=26$ patients $)$
A

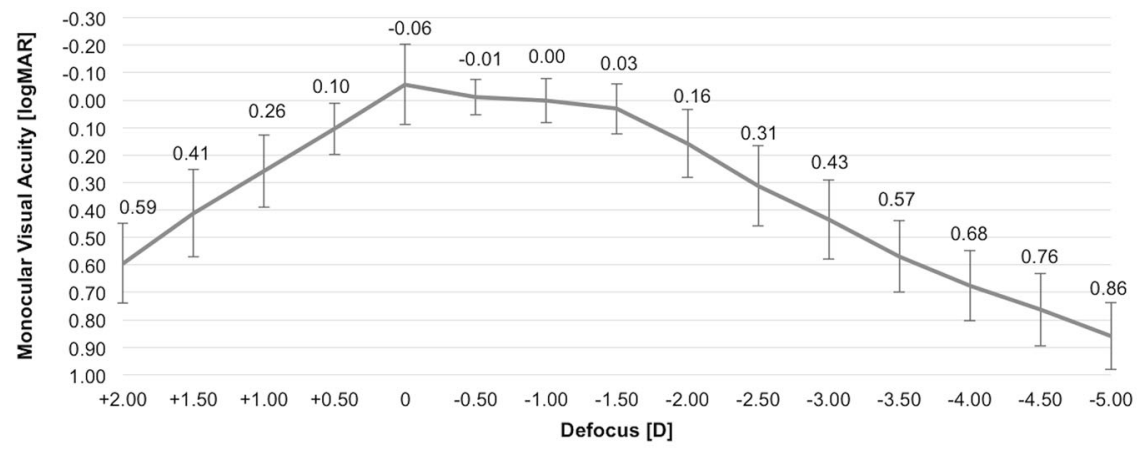

B

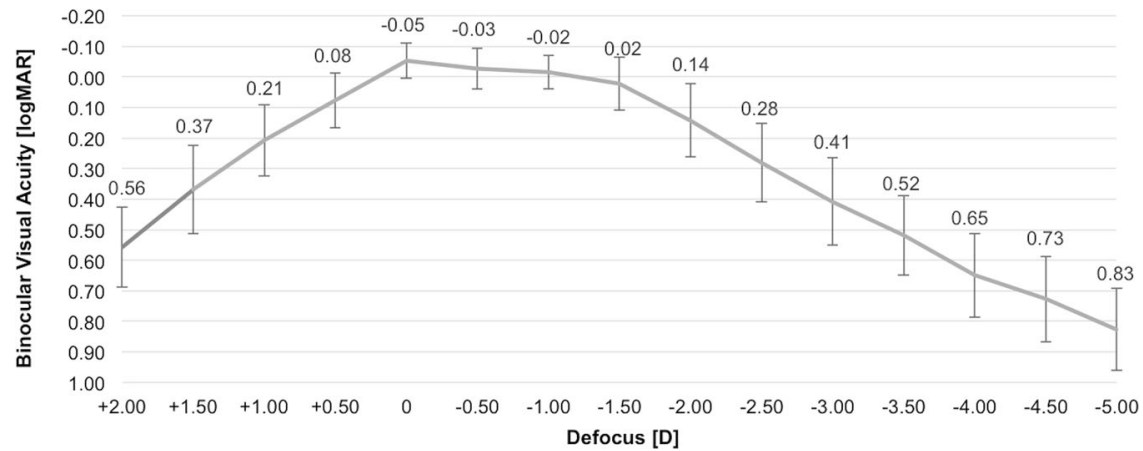

(very good) to 6 (very bad), they rated their total uncorrected vision for activities of daily life with a mean score of $1.6 \pm 0.884$. The mean scores for far distance, intermediate and near activities were $1.58 \pm 0.325,1.63 \pm 0.083$ and $1.98 \pm 0.812$, respectively (Table 2 ).

In addition, 20 of 24 patients $(83.3 \%)$ perceived photopic phenomena such as halos $(54.2 \%)$, glare $(33.3 \%)$, colour perception (4.2\%). Four out of 24 patients (16.7\%) did not report any photopic phenomena. No patient reported the perception of double vision $(0.0 \%)$, ghosting $(0.0 \%)$ or distorted vision $(0.0 \%)$.

One hundred percent ( 24 of 24 patients) would choose the same IOL again and also recommend it to others. All patients reported spectacle independence at far and intermediate distance and $29 \%$ (7 of 24 patients) to use reading spectacles for small font sizes. In total $71 \%$ (17 of 24 patients) reported complete spectacle independence.

\section{Discussion}

The optical technology of EDOF IOLs is based on the concept that uses an echelette design to provide good intermediate vision with EDOF between intermediate and far distance. Thus, for patients whose priorities concerning daily life activities are in the intermediate to far distance, EDOF IOLs would be the right choice and recommendation.
Table 2 Subjective scores from patient-responded questionnaire about the quality of vision (QoV) in daily life activities after implantation of an extended depth of focus intraocular lens (Symfony) at 3 months postoperatively

\begin{tabular}{ll}
\hline Situation & $\begin{array}{l}\text { Score }(\text { mean } \pm \text { SD) } \\
(n=24 \text { patients })\end{array}$ \\
\hline Far distance & $1.58 \pm 0.325$ \\
Car driving, day & $1.56 \pm 0.638$ \\
Car driving, night & $2.13 \pm 0.973$ \\
TV & $1.44 \pm 0.662$ \\
Theater, concert & $1.45 \pm 0.724$ \\
At home & $1.29 \pm 0.549$ \\
Intermediate distance & $1.63 \pm 0.083$ \\
Cooking & $1.71 \pm 0.744$ \\
Computer, musical instrument & $1.54 \pm 0.703$ \\
Domestic work & $1.63 \pm 0.616$ \\
Near distance & $1.98 \pm 0.812$ \\
Newspaper & $1.98 \pm 0.812$ \\
Total distance & $1.64 \pm 0.884$ \\
\hline
\end{tabular}

Score range: $1=$ very good to $6=$ very bad

The current prospective study showed very good monocular and binocular UDVA $(0.01 \pm 0.089 \operatorname{logMAR}$, $-0.02 \pm 0.071 \log$ MAR $)$ and DCVA $(-0.05 \pm 0.061 \log -$ MAR, $-0.06 \pm 0.081 \log$ MAR) for the Symfony IOL. This finding is in line with the multicentre Concerto study by 
Cochener et al (2016) measuring a binocular UDVA of $0.03 \pm 0.09 \log$ MAR and DCVA of $-0.02 \pm 0.07 \log$ MAR [15]. Comparing our results to the study results of Attia et al (2017) presenting a median UDVA of $0.03 \log M A R$ and DCVA of -0.08 logMAR also shows comparable results with a median UDVA of $0.00 \log$ MAR and DCVA of $-0.10 \log$ MAR in the current study [16]. Thus, it can be concluded that this EDOF IOL successfully restores UDVA and CDVA as well as other models of multifocal IOLs [17-24] as for example the AT LISA [25] and PanOptix IOL [26].

The monocular and binocular UIVA $(0.04 \pm 0.087 \mathrm{log}$ MAR, $0.03 \pm 0.083 \log$ MAR $)$ and DCIVA $(0.01 \pm 0.077$ $\log$ MAR, $0.01 \pm 0.086 \log$ MAR) at $80 \mathrm{~cm}$ demonstrated excellent results. The results of monocular and binocular UIVA $(0.08 \pm 0.144 \log$ MAR, $0.08 \pm 0.187 \log$ MAR $)$ and DCIVA $(0.08 \pm 0.150 \log$ MAR, $0.09 \pm 0.166 \log M A R)$ at $60 \mathrm{~cm}$ showed slightly worse values, however, still very good results. A study by Ruiz Mesa et al (2017) [27] found comparable VA values in their series for binocular DCIVA at $80 \mathrm{~cm}(0.06 \pm 0.04 \log \mathrm{MAR})$ and $60 \mathrm{~cm}(0.05 \pm 0.04$ $\log$ MAR). The same holds for Ganesh et al (2018) [28], showing good binocular UIVA and DCIVA at $80 \mathrm{~cm}$ $(-0.04 \pm 0.09 \log$ MAR, $0.01 \pm 0.09 \log$ MAR $)$ and slightly worse values at $60 \mathrm{~cm}(0.05 \pm 0.09 \log$ MAR, $0.10 \pm 0.08$ $\log$ MAR). These results are also supported by other previous studies measuring intermediate VA of this EDOF IOL at $70 \mathrm{~cm}$, showing slightly worse values at this distance, for example, Cochener et al (2016) [15] and Monaco et al (2017) [23]. Comparing the monocular UIVA and DCIVA results to the diffractive AT LISA IOL $(0.06 \pm 0.12 \mathrm{log}$ MAR, $0.04 \pm 0.11 \log$ MAR) [25] with preferred intermediate focus at $80 \mathrm{~cm}$ and the PanOptix IOL with preferred intermediate focus at $60 \mathrm{~cm}(0.06 \pm 0.121 \mathrm{log}$ MAR, $0.05 \pm 0.119 \log$ MAR) [26] shows almost identically good results for the EDOF IOL at both intermediate distances.

The mean monocular and binocular UNVA $(0.30 \pm$ $0.145 \log$ MAR, $0.22 \pm 0.153 \log$ MAR) and DCNVA $(0.30 \pm 0.144 \log \mathrm{MAR}, 0.23 \pm 0.126 \log \mathrm{MAR})$ showed acceptable results. These UNVA and DCNVA results are comparable to other recently conducted studies $[15,16,28-31]$ on this EDOF IOL, for example, Pedrotti et al (2016) [30] who find a UNVA and DCNVA of $0.27 \pm$ $0.11 \log$ MAR and $0.33 \pm 0.10 \log$ MAR, respectively. Comparing the results of monocular UNVA and DCNVA to two diffractive trifocal IOLs, namely the AT LISA IOL $(0.09 \pm 0.12 \log$ MAR, $0.06 \pm 0.13 \log$ MAR $) \quad[25]$ and PanOptix IOL $(0.06 \pm 0.107 \log$ MAR, $0.05 \pm 0.095 \log$ MAR) [26], the preferred near focus at $40 \mathrm{~cm}$ shows a lower near VA of delta $0.2 \log$ MAR for this EDOF IOL. This finding is as expected since the EDOF function of the Symfony IOL cannot provide the same function as a near addition would allow. A possible option to overcome the lower near VA of the Symfony IOL compared to other trifocal IOLs would be to target a ,mini-monovision“ in the non-dominant eye if implanted bilaterally. The binocular defocus curve testing confirmed the VA measurements with a maximum peak at $0.00 \mathrm{D}(-0.05 \log \mathrm{MAR})$ and a flat intermediate VA depth of focus range from -0.5 to $-1.5 \mathrm{D}$ of $0.05 \log$ MAR $(-0.03-0.02 \log$ MAR). At near distance from -2.0 to $-2.5 \mathrm{D}(50 \mathrm{~cm}$ to $40 \mathrm{~cm})$, it confirmed results showing a dip of DCVA of 0.14 to $0.28 \log$ MAR.

As expected CS results were best under photopic light conditions $(1.54 \log C S)$. Mean CS of the EDOF IOL showed similar results as the PanOptix (1.55 $\log C S)$ [26] and AT LISA IOL (1.58 $\log C S)$ [25] but lower values compared to an aspheric monofocal IOL (SN60WF, Alcon) (1.80 $\log C S)$ [32]. CS under mesopic conditions without and with glare was lower $(0.86 \log C S, 0.78 \log C S)$ compared to the aspheric IOL (SN60WF, Alcon) and even showed slightly lower values compared to the two diffractive IOLs [25, 26, 32].

The overall QoV rating for daily life activities was good $(1.64 \pm 0.884)$. Daily life activities at far distance such as television, theater, working at home, and car driving at day were rated very good to good and even car driving at was evaluated as good $(2.13 \pm 0.973)$. Comparing car driving at night to two diffractive trifocal IOLs, namely the AT LISA $(3.4 \pm 1.4)$ [25] and PanOptix $(3.0 \pm 1.31)$ [26], showed a better grading of the Symfony IOL. However, when comparing night-driving capabilities of these two trifocal IOLs, it has to be taken into account that in both studies [25, 26], patients with cataract and clear lens exchange were included, unlike the current study in which only patients with cataract were included. This could lead to a bias regarding the comparison of the night-driving capabilities since patients that underwent a clear lens exchange may report a decrease in night vision.

Reading a newspaper was rated as good (1.98 \pm 0.812$)$, which is similar to ratings of the trifocal IOLs PanOptix $(1.9 \pm 1.36)$ and AT LISA $(2.4 \pm 1.1)$ [25, 26, 32].

At the 3 months postoperative visit, $16.7 \%$ of the patients experienced no photopic phenomena, whereas $54.2 \%$ reported halos and $33.3 \%$ perceived glare on direct questioning. Compared to the perception of photopic phenomena after 3 months of other multifocal IOLs, these rates can be evaluated as rather good [17, 25, 26, 33, 34].

Spectacle independence was achieved in $100 \%$ for distance and intermediate vision and $71 \%$ of patients at near distance, whereas patients reported using reading spectacles only for small font sizes. That $100 \%$ would choose the same IOL again and would also recommend it to other patients underlines the high levels of patient satisfaction.

The study's limitations include small sample size, lack of control group, and a short follow-up duration of only 
3 months. The study is susceptible to possible selection bias since patients were included in the study after having completed the surgery. A randomized controlled study would have possibly provided more meaningful results, but the fact that the study was not sponsor financed but rather independently performed in a university setting did not allow randomization of patients since the patients had to cover the costs for their refractive surgery and lens. In this setting a preoperative randomization and choice of lens was unfortunately not possible. A final limitation is the modified, unvalidated quality of vision questionnaire.

In conclusion, this study shows that the EDOF IOL provides good intermediate and far UCVA and acceptable near UCVA. The binocular defocus curve confirmed this finding with a very good EDOF between far and intermediate distance and a dip at the near distance. Finally, it provides good QoV, CS, high spectacle independence and satisfaction with particularly good night-driving capabilities. The study highlights that, regarding treatment selection, this EDOF IOL can be recommended to patients with very high VA priorities at far to intermediate distance, who are also looking for acceptable near vision, and who need good night-driving capabilities with a low perception of photopic phenomena.

\section{Summary}

\section{What was known before}

- An extended depth of focus (EDOF) IOL provides successful visual restoration with good visual outcomes across all distances. The visual performance of an EDOF IOL is associated with a minimal level of disturbing photic phenomena and high levels of spectacle independence.

\section{What this study adds}

- The EDOF IOL provides excellent intermediate and far vision with a slight drop in visual acuity at near distance. The EDOF IOL provides good contrast sensitivity and perception of few optical phenomena with good nightdriving capabilities.

\section{Funding Support: No funding support to report.}

Financial Disclosures: $\mathrm{T}$ Kohnen: Consultant and Research for Abbott/J\&J, Alcon/Novartis, Avedro, Oculentis, Oculus, Presbia, Schwind, and Zeiss. Consultant for Allergan, Bausch \& Lomb, Dompé, Geuder, Merck, Rayner, Santen, Staar, Thea, Tear Lab, Thieme and Ziemer. Research for Hoya.

\section{Compliance with ethical standards}

Conflict of interest Myriam Böhm, Eva Hemkeppler, Nina DeLorenzo, Sabrina Schönbrunn, Michael Herzog, Kerstin Petermann have no financial interests to disclose. All authors attest that they meet the current ICMJE criteria for authorship. This research did not receive any specific grants from funding agencies in the public, commercial, or not-for-profit sectors.

Publisher's note: Springer Nature remains neutral with regard to jurisdictional claims in published maps and institutional affiliations.

\section{References}

1. Hutz WW, Eckhardt HB, Rohrig B, Grolmus R. Intermediate vision and reading speed with array, Tecnis, and ReSTOR intraocular lenses. J Refract Surg (Thorofare, N J: 1995). 2008;24:251-6.

2. Wilkins MR, Allan BD, Rubin GS, et al. Randomized trial of multifocal intraocular lenses versus monovision after bilateral cataract surgery. Ophthalmology. 2013;120:2449-55.e1.

3. Aurich H, Pham DT. [Individualised correction of presbyopia by the use of phacoemulsification: monovision and multifocal lenses]. Klin Mon fur Augenheilkd. 2014;231:1004-7.

4. Alio JL, Plaza-Puche AB, Fernandez-Buenaga R, Pikkel J, Maldonado M. Multifocal intraocular lenses: an overview. Surv Ophthalmol. 2017;62:611-34.

5. Auffarth GU, Rabsilber TM, Kohnen T, Holzer MP. [Design and optical principles of multifocal lenses]. DerOphthalmologe. 2008;105:522-6.

6. Cochener B, Lafuma A, Khoshnood B, Courouve L, Berdeaux G. Comparison of outcomes with multifocal intraocular lenses: a meta-analysis. Clin Ophthalmol. 2011;5:45-56.

7. Mendicute J, Kapp A, Levy P, et al. Evaluation of visual outcomes and patient satisfaction after implantation of a diffractive trifocal intraocular lens. J cataract Refract Surg. 2016;42:203-10.

8. de Silva SR, Evans JR, Kirthi V, Ziaei M, Leyland M. Multifocal versus monofocal intraocular lenses after cataract extraction. Cochrane database Syst Rev. 2016;12:Cd003169.

9. Gatinel D, Loicq J. Clinically relevant optical properties of bifocal, trifocal, and extended depth of focus intraocular lenses. J Refract Surg. 2016;32:273-80.

10. Ferris FL 3rd, Bailey I. Standardizing the measurement of visual acuity for clinical research studies: guidelines from the Eye Care Technology Forum. Ophthalmology. 1996;103:181-2.

11. Buhren J, Terzi E, Bach M, Wesemann W, Kohnen T. Measuring contrast sensitivity under different lighting conditions: comparison of three tests. Optom Vis Sci. 2006;83:290-8.

12. Kohnen T, Nuijts R, Levy P, Haefliger E, Alfonso JF. Visual function after bilateral implantation of apodized diffractive aspheric multifocal intraocular lenses with $\mathrm{a}+3.0 \mathrm{D}$ addition. J cataract Refract Surg. 2009;35:2062-9.

13. Mangione CM, Lee PP, Gutierrez PR, Spritzer K, Berry S, Hays RD. Development of the 25-list-item national eye institute visual function questionnaire. Arch Ophthalmol. 2001; 119:1050-58.

14. Javitt JC, Wang F, Trentacost DJ, Rowe M, Tarantino N. Outcomes of cataract extraction with multifocal intraocular lens implantation: functional status and quality of life. Ophthalmology. 1997;104:589-99.

15. Cochener B. Clinical outcomes of a new range of vision intraocular lens: International Multicenter Concerto Study. J cataract Refract Surg. 2016;42:1268-75. 
16. Attia MSA, Auffarth GU, Kretz FTA, et al. Clinical evaluation of an extended depth of focus intraocular lens with the salzburg reading desk. J Refract Surg. 2017;33:664-69.

17. Law EM, Aggarwal RK, Kasaby H. Clinical outcomes with a new trifocal intraocular lens. Eur J Ophthalmol. 2014;24: 501-8.

18. Mojzis P, Pena-Garcia P, Liehneova I, Ziak P, Alio JL. Outcomes of a new diffractive trifocal intraocular lens. J cataract Refract Surg. 2014;40:60-9.

19. Sheppard AL, Shah S, Bhatt U, Bhogal G, Wolffsohn JS. Visual outcomes and subjective experience after bilateral implantation of a new diffractive trifocal intraocular lens. J cataract Refract Surg. 2013;39:343-9.

20. Alio JL, Montalban R, Pena-Garcia P, Soria FA, Vega-Estrada A. Visual outcomes of a trifocal aspheric diffractive intraocular lens with microincision cataract surgery. J Refract Surg. 2013;29: 756-61.

21. Alfonso JF, Fernandez-Vega Cueto L, Belda-Salmeron L, Montes-Mico R, Fernandez-Vega L. Visual function after implantation of a diffractive aspheric trifocal intraocular lens. Eur J Ophthalmol. 2016;26:405-11.

22. Garcia-Perez JL, Gros-Otero J, Sanchez-Ramos C, Blazquez V, Contreras I. Short term visual outcomes of a new trifocal intraocular lens. BMC Ophthalmol. 2017;17:72.

23. Monaco G, Gari M, Di Censo F, Poscia A, Ruggi G, Scialdone A. Visual performance after bilateral implantation of 2 new presbyopia-correcting intraocular lenses: Trifocal versus extended range of vision. J cataract Refract Surg. 2017;43:737-47.

24. Alfonso JF, Fernandez-Vega Cueto L, Belda-Salmeron L, Montes-Mico R, Fernandez-Vega L. Visual function after implantation of a diffractive aspheric trifocal intraocular lens. Eur J Ophthalmol. 2016;26:405-11.

25. Kohnen T, Titke C, Bohm M. Trifocal intraocular lens implantation to treat visual demands in various distances following lens removal. Am J Ophthalmol. 2016;161:71-7.e1.
26. Kohnen T, Herzog M, Hemkeppler E, et al. Visual performance of a quadrifocal (trifocal) intraocular lens following removal of the crystalline Lens. Am J Ophthalmol. 2017;184:52-62.

27. Ruiz-Mesa R, Abengozar-Vela A, Aramburu A, Ruiz-Santos M. Comparison of visual outcomes after bilateral implantation of extended range of vision and trifocal intraocular lenses. Eur J Ophthalmol. 2017;27:460-65.

28. Ganesh S, Brar S, Pawar A, Relekar KJ. Visual and refractive outcomes following bilateral implantation of extended range of vision intraocular lens with micromonovision. J Ophthalmol. 2018;2018:7321794.

29. Ruiz-Mesa R, Abengozar-Vela A, Ruiz-Santos M. A comparative study of the visual outcomes between a new trifocal and an extended depth of focus intraocular lens. Eur J Ophthalmol. 2017;28:182-7.

30. Pedrotti E, Bruni E, Bonacci E, Badalamenti R, Mastropasqua R, Marchini G. Comparative analysis of the clinical outcomes with a monofocal and an extended range of vision intraocular lens. J Refract Surg. 2016;32:436-42.

31. de Medeiros AL, de Araujo Rolim AG, Motta AFP, et al. Comparison of visual outcomes after bilateral implantation of a diffractive trifocal intraocular lens and blended implantation of an extended depth of focus intraocular lens with a diffractive bifocal intraocular lens. Clin Ophthalmol (Auckl, N Z). 2017; 11:1911-16.

32. Kohnen T, Klaproth OK, Buhren J. Effect of intraocular lens asphericity on quality of vision after cataract removal: an intraindividual comparison. Ophthalmology. 2009;116:1697-706.

33. Chang JS, Ng JC, Lau SY. Visual outcomes and patient satisfaction after presbyopic lens exchange with a diffractive multifocal intraocular lens. J Refract Surg. 2012;28:468-74.

34. Kretz FT, Choi CY, Muller M, Gerl M, Gerl RH, Auffarth GU. Visual outcomes, patient satisfaction and spectacle independence with a trifocal diffractive intraocular lens. Korean J Ophthalmol. 2016;30:180-91. 